\title{
Impact of type 2 diabetes mellitus on mid-term mortality for hypertrophic cardiomyopathy patients who underwent septal myectomy
}

Shengwei Wang ${ }^{1}$, Hao Cui ${ }^{2}$, Keshan $\mathrm{Ji}^{3}$, Changpeng Song ${ }^{3}$, Changwei Ren ${ }^{1}$, Hongchang Guo ${ }^{1}$, Changsheng Zhu', Shuiyun Wang ${ }^{4^{*}}$ and Yongqiang Lai ${ }^{*}$

\begin{abstract}
Background: Type 2 diabetes mellitus is common in cardiovascular disease. It is associated with adverse clinical outcomes for patients who had undergone coronary artery bypass and valve operations. The aim of this study was to evaluate the impact of type 2 diabetes mellitus on the midterm outcomes of patients with hypertrophic cardiomyopathy who underwent septal myectomy.

Methods: We retrospectively analyzed the data of 67 hypertrophic cardiomyopathy patients with type 2 diabetes mellitus who underwent septal myectomy from two medical centers in China from 2011 to 2018. A propensity scorematched cohort of 134 patients without type 2 diabetes mellitus was also analyzed.

Results: During a median follow-up of 28.0 (interquartile range: 13.0-3.0) months, 9 patients died. The cause of death of all of these patients was cardiovascular, particularly sudden cardiac death in 3 patients. Patients with type 2 diabetes mellitus had a higher rate of sudden cardiac death ( $4.5 \%$ vs. $0.0 \%, p=0.04)$. The Kaplan-Meier survival analysis revealed that the rates of predicted 3-year survival free from cardiovascular death $(98.1 \%$ vs. $95.1 \%, p=0.14)$ were similar between the two groups. However, the rates of predicted 3-year survival free from sudden cardiac death (100\% vs. $96.7 \%, p=0.01)$ were significantly higher in hypertrophic cardiomyopathy patients without type 2 diabetes mellitus than in those with type 2 diabetes mellitus. Furthermore, after adjustment for age and sex, only N-terminal pro-brain natriuretic peptide (hazards ratio: 1.002, 95\% confidence interval: 1.000-1.005, $p=0.02$ ) and glomerular filtration rate $\leq 80 \mathrm{ml} / \mathrm{min}$ (hazards ratio: $3.23,95 \%$ confidence interval: $1.34-7.24, p=0.047$ ) were independent risk factors for hypertrophic cardiomyopathy patients with type 2 diabetes mellitus.
\end{abstract}

\footnotetext{
*Correspondence: wsymd@sina.com; yongqianglai@yahoo.com

${ }^{1}$ Department of Cardiovascular Surgery Center, Beijing Anzhen Hospital,

Capital Medical University, Beijing Institute of Heart, Lung and Blood

Vascular Diseases, No. 2, Anzhen Road, Chaoyang District, Beijing 100029,

China

${ }^{4}$ Department of Cardiovascular Surgery, State Key Laboratory

of Cardiovascular Disease, Fuwai Hospital, National Center

for Cardiovascular Diseases, Chinese Academy of Medical Sciences

and Peking Union Medical College, No. 167, Beilishi Road, Xicheng

District, Beijing 100037, China

Full list of author information is available at the end of the article
}

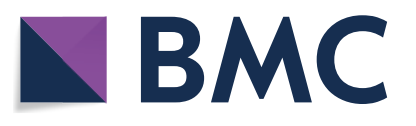

(c) The Author(s) 2020. This article is licensed under a Creative Commons Attribution 4.0 International License, which permits use, sharing, adaptation, distribution and reproduction in any medium or format, as long as you give appropriate credit to the original author(s) and the source, provide a link to the Creative Commons licence, and indicate if changes were made. The images or other third party material in this article are included in the article's Creative Commons licence, unless indicated otherwise in a credit line to the material. If material is not included in the article's Creative Commons licence and your intended use is not permitted by statutory regulation or exceeds the permitted use, you will need to obtain permission directly from the copyright holder. To view a copy of this licence, visit http://creativeco mmons.org/licenses/by/4.0/. The Creative Commons Public Domain Dedication waiver (http://creativecommons.org/publicdomain/ zero/1.0/) applies to the data made available in this article, unless otherwise stated in a credit line to the data. 
Conclusions: Hypertrophic cardiomyopathy patients with and without type 2 diabetes mellitus have similar 3-year cardiovascular mortality after septal myectomy. However, type 2 diabetes mellitus is associated with higher sudden cardiac death rate in these patients. In addition, $\mathrm{N}$-terminal pro-brain natriuretic peptide and glomerular filtration rate $\leq 80 \mathrm{ml} / \mathrm{min}$ were independent risk factors among hypertrophic cardiomyopathy patients with type 2 diabetes mellitus.

Keywords: Type 2 diabetes mellitus, Hypertrophic cardiomyopathy, Septal myectomy, Sudden cardiac death, Cardiovascular death

\section{Background}

Hypertrophic cardiomyopathy ( $\mathrm{HCM})$ is a disease state characterized by unexplained left ventricular (LV) hypertrophy associated with nondilated ventricular chambers in the absence of other cardiac or systemic diseases. It is considered a common inherited heart disease and has a population prevalence of 1 in 500 [1,2]. Approximately two-thirds of patients have left ventricular outflow tract (LVOT) obstruction known as hypertrophic obstructive cardiomyopathy (HOCM). If the symptoms of these patients are refractory to optimal medical therapy, surgery is recommended.

Diabetes mellitus (DM) is highly common among patients with cardiovascular disease and is associated with increased burden of morbidity and hospitalization [3]. The functional changes occurring in DM can significantly alter the hemodynamic stress on the heart. It is an established risk factor for cardiovascular disease and increases the risk of cardiovascular mortality [4]. In addition, previous studies have reported that type 2 DM (T2DM) is associated with adverse cardiovascular events after coronary artery bypass and valve operations [5-7]. However, the effect of T2DM on clinical outcomes for HCM patients who had undergone septal myectomy is not well studied. We aimed to evaluate the effect of T2DM on the clinical outcomes of patients who underwent septal myectomy.

\section{Methods}

\section{Aim, design, and setting}

The objective of this study was to evaluate the effect of T2DM on the clinical outcomes of patients who underwent septal myectomy. This retrospective study was performed using data from two medical centers in Beijing, China.

\section{Study population}

We retrospectively studied the data of 67 patients with HOCM and T2DM from Fuwai Hospital (47 patients) and Anzhen Hospital (20 patients) between 2011 and 2018. A control group (patients without DM) was generated from the two centers and the patients were matched in a ratio of 2:1 based on age, sex, body mass index (BMI), and prevalence of hypertension and hyperlipemia. These patients were randomly selected from subjects who underwent septal myectomy during the same period. The diagnostic criteria of HCM mainly included an unexplained septal hypertrophy with a thickness more than $15 \mathrm{~mm}$ according to guidelines $[1,2]$. The indications for septal myectomy were severe symptoms or syncope or near-syncope despite optimal medical therapy and LVOT gradient $>50 \mathrm{mmHg}$ at rest or with provocation. The diagnosis of DM was obtained from the clinical chart at the time of evaluation. The details of the surgical methods were described in our previous studies $[8$, 9]. Concomitant procedures were performed according to the results of the preoperative evaluation and intraoperative exploration. History of non-sustained ventricular tachycardia (NSVT; defined as an episode of consecutive ventricular beats with a rate of at least $100 \mathrm{bpm}$ and a maximum episode length of $30 \mathrm{~s}$ ) and atrial fibrillation (AF) was recorded, based on history, electrocardiograms, and Holter monitoring in all patients.

\section{Echocardiography and cardiovascular magnetic resonance imaging}

Echocardiographic examinations were performed on patients using an E9 ultrasound system. The thicknesses of the interventricular septum and ventricular wall were determined during diastole. Aside from the maximum thickness, the representative interventricular septal thickness, which is usually the thickness of the point $25 \mathrm{~mm}$ under the right coronary sinus nadir, was also recorded to indicate overall thickness. The LVOT gradient was calculated using the simplified Bernoulli equation. Pulmonary hypertension was defined as a pulmonary artery systolic pressure $\geq 35 \mathrm{mmHg}$. The measurements of left ventricular ejection fraction (LVEF) were determined by following the American Society of Echocardiography recommendations [10].

Cardiovascular magnetic resonance (CMR) examinations were performed using a 1.5-T MR scanner (Magnetom Avanto; Siemens Medical Solutions, Erlangen, Germany). Cine scans in cardiac short- and long-axis views were acquired by applying true imaging with steady-stage precession sequence (TrueFISP). Image 
analysis using a commercial imaging workstation (Siemens Medical Systems). LVEF and indexed LV mass and volume were measured by analyzing the short-axis cine image. The inner and outer myocardial edges were manually delineated. Late gadolinium enhancement (LGE) was determined semi-automatically as a percentage of the total myocardium and defined as having an intensity $>6$ standard deviation above the normal myocardium according to a previous study [11]. Right ventricular ejection fraction (RVEF) was measured using volumetric measurements on CMR [12].

\section{Laboratory measurements}

A fasting blood sample was obtained from all patients on the second day of hospitalization. The levels of highsensitivity C-reactive protein (hs-CRP), creatinine, lowdensity lipoprotein, and high-density lipoprotein were monitored. We estimated the glomerular filtration rate using the CKD-EPI equation: $\mathrm{a} \times($ serum creatinine/b) $\mathrm{c} \times(0.993)$ age, where a was 144 and 141 for women and men, respectively; b was 0.7 and 0.9 for women and men, respectively; c was -0.329 and -1.209 if the creatinine level was $<0.7$ and $>0.7 \mathrm{mg} / \mathrm{dL}$, respectively, for women, and -0.411 and -1.209 if the creatinine level was $<0.7 \mathrm{mg} / \mathrm{dL}$ and $>0.7 \mathrm{mg} / \mathrm{dL}$, respectively, for men.

\section{Follow-up data}

Clinical status of the study patients was obtained through telephone interviews at least once a year after septal myectomy. Those subjects who died were treated as the endpoints, and the follow-up time was defined as their dead time. The last follow-up of survivors was conducted in December 2018. The causes of death were sudden cardiac death (SCD), death related to congestive heart failure and other cardiovascular disease, or noncardiac death. Because there were no noncardiac deaths in these patients, the survival analysis used in the present study only included cardiovascular death and SCD.

\section{Statistical analysis}

In the present study, we performed a propensity score match for the main variables found to differ significantly $(\mathrm{p}<0.05)$ according to diabetes status: age, sex, BMI, hypertension, and hyperlipemia. Matching was performed using the nearest neighbour method, assigning patients with diabetes and without diabetes in a 1:2 ratio, with a 0.2 caliper width. The equalization test after matching are shown in Additional file 1: Table S1 and Additional file 2: Figure S1.

Results are presented as mean \pm standard deviation, median (interquartile range [IQR]), or percentage, as appropriate. Student t-test and Mann-Whitney U test for matched samples were used to compare continuous variables, and the $\chi^{2}$ and Fisher's exact test were used to compare classification variables, as appropriate. The Kaplan-Meier method was used to calculate survival free from cardiovascular death and compare SCD between the two groups. A log-rank test was used to compare survival curves between the two groups. A stepwise multiple Cox analysis technique was used to identify the variables independently associated with cardiovascular death in these patients which were incorporated into the final models. Age, sex, and variables with $\mathrm{p}<0.1$ on the univariable analysis were added to the multivariable analysis. All reported probability values were two-tailed, and $\mathrm{p}<0.05$ was considered statistically significant. SPSS version 26.0 statistical software (IBM Corp., Armonk, NY, USA) and R version 3.5.0 (R Foundation for Statistical Computing, Vienna, Austria) were used for calculations and illustrations in the present study.

\section{Results}

Preoperative and perioperative patient characteristics A total of $201 \mathrm{HOCM}$ patients (with T2DM, 67 patients; without T2DM, 134) were included. We compared the baseline characteristics between the two groups (Table 1). Compared with patients without DM, those with HOCM and DM had a lower glomerular filtration rate and hs-CRP level. There was no difference in symptoms, including chest pain, palpitation, and syncope, between the two groups. In addition, the prevalence of AF was significantly higher in patients with $\mathrm{HOCM}$ and T2DM than in those with HOCM alone. Of the 67 patients with T2DM, 19 (28.4\%) were treated with insulin, 39 (58.2\%) were treated with metformin, 9 (13.4\%) patients were treated with acarbose, and 3 (4.5) patients were treated with metformin and acarbose. In addition, the baseline characteristics of patients with and without T2DM before matching are shown in Additional file 3: Table S2.

The perioperative period was 30 days after the operation. Patients with HCM and T2DM had a higher proportion of coronary artery bypass and maze procedures. The immediate postoperative LVOT gradient was higher in patients with HCM and T2DM. Only one patient died during the perioperative period in the T2DM group $(0 \%$ vs. $1.5 \%, \mathrm{p}=0.33$ ). However, the other parameters did not differ between the two groups during the perioperative period. Detailed information is shown in Table 2.

\section{CMR findings}

In the present study, 150 patients underwent CMR. As shown in Table 3, the RVEF was higher in patients without T2DM, whereas the other parameters, including the percentage of LGE, did not differ between the two groups. 
Table 1 Baseline patient characters

\begin{tabular}{|c|c|c|c|}
\hline Variable & No diabetes $(n=134)$ & Diabetes $(n=67)$ & $p$ value \\
\hline Age, years & $48.8 \pm 13.5$ & $50.1 \pm 13.8$ & 0.53 \\
\hline Male, $n$ & $78(58.2 \%)$ & $41(61.2 \%)$ & 0.69 \\
\hline Body mass index, kg/m² & $25.9 \pm 3.9$ & $25.6 \pm 3.7$ & 0.69 \\
\hline Family history of HCM or SCD, $\mathrm{n}$ & $18(13.4 \%)$ & $15(22.4 \%)$ & 0.11 \\
\hline Heart rate, beats/min & $72.2 \pm 9.3$ & $72.7 \pm 8.5$ & 0.71 \\
\hline BNP, pg/mL & $1379.9(636.3-2342.4)$ & $1605.5(573.7-2726.3)$ & 0.71 \\
\hline Creatinine, umol/L & $77.3 \pm 13.4$ & $76.8 \pm 14.8$ & 0.83 \\
\hline Glomerular filtration rate, $\mathrm{ml} / \mathrm{min}$ & $99.8 \pm 20.2$ & $93.7 \pm 18.5$ & 0.04 \\
\hline $\mathrm{Hs}-\mathrm{CRP}, \mathrm{mg} / \mathrm{L}$ & $0.97(0.40-1.80)$ & $1.30(0.56-2.28)$ & 0.04 \\
\hline $\mathrm{LDL}, \mathrm{mmol} / \mathrm{L}$ & $2.6 \pm 0.9$ & $2.5 \pm 0.6$ & 0.31 \\
\hline $\mathrm{HDL}, \mathrm{mmol} / \mathrm{L}$ & $1.2 \pm 0.5$ & $1.16 \pm 0.3$ & 0.63 \\
\hline \multicolumn{4}{|l|}{ Comorbidities } \\
\hline Hypertension, n & $54(40.3 \%)$ & $28(41.8 \%)$ & 0.84 \\
\hline Hyperlipemia, n & $28(20.9 \%)$ & $15(22.4 \%)$ & 0.81 \\
\hline \multicolumn{4}{|l|}{ Clinical presentation } \\
\hline Chest pain, $\mathrm{n}$ & $35(26.1 \%)$ & $20(29.9 \%)$ & 0.58 \\
\hline Palpitation, $\mathrm{n}$ & $11(8.2 \%)$ & $8(11.9 \%)$ & 0.39 \\
\hline Syncope, $n$ & $14(10.4 \%)$ & $8(11.9 \%)$ & 0.75 \\
\hline Atrial fibrillation, n & $16(11.9 \%)$ & $19(28.4 \%)$ & 0.004 \\
\hline \multicolumn{4}{|l|}{ Echocardiographic indices } \\
\hline LVEDD, mm & $41.8 \pm 5.7$ & $41.5 \pm 4.5$ & 0.70 \\
\hline IVST, mm & $20.3 \pm 5.6$ & $20.0 \pm 5.8$ & 0.74 \\
\hline Posterior wall, mm & $11.9 \pm 2.4$ & $12.2 \pm 2.9$ & 0.56 \\
\hline LVEF, \% & $71.4 \pm 5.6$ & $71.3 \pm 5.4$ & 0.94 \\
\hline IVST $\geq 30 \mathrm{~mm}, \mathrm{n}$ & $11(8.2 \%)$ & $4(6.0 \%)$ & 0.57 \\
\hline Moderate or severe MR & $24(17.9 \%)$ & $7(10.4 \%)$ & 0.17 \\
\hline \multicolumn{4}{|l|}{ Medical therapy } \\
\hline Beta-blockers, n & 99 (73.9\%) & $50(74.6 \%)$ & 0.91 \\
\hline Calcium-channel blockers, n & $7(5.2 \%)$ & $7(10.4 \%)$ & 0.17 \\
\hline ACEI/ARB, n & $17(12.7 \%)$ & $8(11.9 \%)$ & 0.88 \\
\hline Statins, n & $14(10.4 \%)$ & $11(16.4 \%)$ & 0.23 \\
\hline Insulin, n & - & 19 (28.4\%) & - \\
\hline Metformin, $n$ & - & $39(58.2 \%)$ & - \\
\hline Acarbose, $n$ & - & $12(17.9 \%)$ & - \\
\hline
\end{tabular}

Values are presented as percentage, mean $\pm S D$, or median (interquartile range) when appropriate

IVST interventricular septal thickness, HCM hypertrophic myocardiopathy; SCD sudden cardiac death, NYHA New York Heart Association, BNP brain natriuretic peptide, LVEF left ventricular ejection fraction, $L D L$ low density lipoprotein, $H D L$ high density lipoprotein, $L V E D D$ left ventricular end diastole diameter, $L V O T$ left ventricular outflow tract, $M R$ mitral regurgitation, $A C E I / A R B$ angiotensin-converting enzyme inhibitor or angiotensin receptor blocker

\section{Follow-up data}

The follow-up data are shown in Table 4. The percentage of New York Heart Association class III or IV did not differ between baseline and at the last follow-up. At baseline, the proportions of NSVT and left atrium diameter $\geq 45 \mathrm{~mm}$ were higher in patients with HOCM and T2DM. However, the prevalence of NSVT remained high in these patients after surgery, whereas left atrium diameter $\geq 45 \mathrm{~mm}$ had no difference after surgery. Importantly, the incidence of pulmonary hypertension did not differ preoperatively, but increased significantly during follow-up in patients with T2DM. In addition, patients with HOCM and T2DM had a higher LVOT gradient at baseline.

\section{Outcomes and mortality}

During a median follow-up of 28.0 (IQR: 13.0-53.0) months, 9 patients died. In this study cohort, the cause of death in these patients was cardiovascular death, including $3 \mathrm{SCD}, 4$ deaths related to heart failure, 1 death due 
Table 2 Perioperative data between two groups

\begin{tabular}{llll}
\hline Variable & No diabetes $(\mathbf{n}=\mathbf{1 3 4})$ & Diabetes $(\mathbf{n}=\mathbf{6 7})$ & $\mathbf{p}$ value \\
\hline Concomitant procedures & & & \\
Mitral valve procedure, $\mathrm{n}$ & $22(16.4 \%)$ & $9(13.4 \%)$ & 0.58 \\
Tricuspid valvuloplasty, $\mathrm{n}$ & $15(11.2 \% \wedge)$ & $7(10.4 \%)$ & 0.87 \\
CABG, $\mathrm{n}$ & $6(4.5 \%)$ & $8(11.9 \%)$ & 0.05 \\
Maze procedure, $\mathrm{n}$ & $5(3.7 \%)$ & $8(11.9 \%)$ & 0.03 \\
Cardiopulmonary bypass time, min & $107.6 \pm 47.1$ & $113.3 \pm 51.2$ & 0.43 \\
Aortic crossclamping time, min & $72.7 \pm 36.4$ & $76.8 \pm 35.9$ & 0.45 \\
Postoperative ventilation time, min & $17.0(13.0-21.0)$ & $17.0(13.0-24.0)$ & 0.98 \\
Postoperative hospital stays, day & $8.4 \pm 3.8$ & $8.4 \pm 4.2$ & 0.96 \\
Post-operative LVOT gradient, $\mathrm{mmHg}$ & $6.6 \pm 2.7$ & $7.6 \pm 3.4$ & 0.04 \\
Perioperative death & $0(0.0 \%)$ & $1(1.5 \%)$ & 0.33 \\
\hline
\end{tabular}

Values are presented as percentage, mean $\pm S D$, or median (interquartile range) when appropriate

$C A B G$ coronary artery bypass graft, ICU intensive care unit

Table 3 Parameters of cardiac magnetic resonance

\begin{tabular}{llll}
\hline Variable & No diabetes $(\mathbf{n}=\mathbf{9 8})$ & Diabetes $(\mathbf{n}=\mathbf{5 2})$ & p value \\
\hline RVEF, \% & $47.5 \pm 7.8$ & $43.9 \pm 8.6$ & 0.01 \\
Maximal ISVT, mm & $22.2 \pm 5.3$ & $22.1 \pm 5.1$ & 0.91 \\
Indexed LV mass, $\mathrm{g} / \mathrm{m}^{2}$ & $99.1 \pm 36.2$ & $92.3 \pm 38.1$ & 0.28 \\
Indexed LV volume, $\mathrm{ml} / \mathrm{m}^{2}$ & $93.7 \pm 36.9$ & $87.9 \pm 36.3$ & 0.29 \\
Indexed LGE mass, $\mathrm{g} / \mathrm{m}^{2}$ & $7.3(3.5-15.8)$ & $8.4(3.9-15.6)$ & 0.98 \\
Indexed LGE volume, $\mathrm{ml} / \mathrm{m}^{2}$ & $6.9(3.3-15.1)$ & $8.0(3.7-14.9)$ & 0.97 \\
LGE \%, \% of LV mass & $7.9(4.1-17.9)$ & $8.3(5.5-14.8)$ & 0.77 \\
\hline
\end{tabular}

Values are presented as percentages, mean $\pm S D$, or median (interquartile range), when appropriate

RVEF right ventricular ejection fraction, IVST interventricular septal thickness, LGE Late Gadolinium Enhancement

Table 4 Baseline and last follow-up data

\begin{tabular}{|c|c|c|c|}
\hline Variables & No diabetes $(n=134)$ & Diabetes $(n=67)$ & $\mathrm{p}$ value \\
\hline \multicolumn{4}{|l|}{ NYHA class III or IV, n } \\
\hline Baseline & $104(77.6 \%)$ & $54(80.6 \%)$ & 0.63 \\
\hline Last follow-up & $6(4.5 \%)$ & $7(10.4 \%)$ & 0.11 \\
\hline \multicolumn{4}{|l|}{ Pulmonary hypertension, $\mathrm{n}$} \\
\hline Baseline & $17(12.7 \%)$ & $5(7.5 \%)$ & 0.26 \\
\hline Last follow-up & $3(2.2 \%)$ & $7(10.4 \%)$ & 0.02 \\
\hline \multicolumn{4}{|l|}{ NSVT, n } \\
\hline Baseline & $15(11.2 \%)$ & $15(22.4 \%)$ & 0.04 \\
\hline Last follow-up & $2(1.5 \%)$ & $5(7.5 \%)$ & 0.04 \\
\hline \multicolumn{4}{|l|}{ LVOT gradient, mmHg } \\
\hline Baseline & $83.3 \pm 26.3$ & $93.2 \pm 36.8$ & 0.03 \\
\hline Last follow-up & $11.6 \pm 8.4$ & $12.2 \pm 8.5$ & 0.64 \\
\hline \multicolumn{4}{|l|}{ Left atrium $\geq 45 \mathrm{~mm}, \mathrm{n}$} \\
\hline Baseline & $47(35.1 \%)$ & $33(49.3 \%)$ & 0.05 \\
\hline Last follow-up & $37(27.6 \%)$ & $17(25.4 \%)$ & 0.74 \\
\hline Death, $\mathrm{n}$ & $4(3.0 \%)$ & $5(7.5 \%)$ & 0.16 \\
\hline Sudden cardiac death, $\mathrm{n}$ & $0(0 \%)$ & $3(4.5 \%)$ & 0.04 \\
\hline
\end{tabular}

Values are presented as percentage, mean $\pm \mathrm{SD}$, or median (interquartile range) when appropriate

NYHA New York Heart Association, NSVT non-sustained ventricular tachycardia, LVOT left ventricular outflow tract, LVEDD left ventricular end diastole diameter 
to infective endocarditis, and 1 death due to myocardial infarction. Patients with diabetes had a significantly high rate of SCD ( $4.5 \%$ vs. $0.0 \%, p=0.04)$. The Kaplan-Meier survival analysis revealed no difference in the rates of predicted 3-year survival free from cardiovascular death (98.1\% vs. 95.1\%, $\mathrm{p}=0.14$ ) (Fig. 1). However, the rate of predicted 3-year survival free from SCD (100\% vs $96.7 \%$, $\mathrm{p}=0.013)$ was lower in patients with HOCM and T2DM than in those without T2DM (Fig. 2). Furthermore, we analyzed the factors associated with cardiovascular death in patients with HOCM and T2DM. The univariable analysis revealed that history of NSVT (hazards ratio [HR]: $1.51,95 \%$ confidence interval $[\mathrm{CI}]: 1.31-1.73, \mathrm{p}=0.03)$, glomerular filtration rate $\leq 80 \mathrm{ml} / \mathrm{min}$ (HR:4.84, 95\% CI 1.42-19.36, $\mathrm{p}=0.02)$, $\mathrm{N}$-terminal pro-brain natriuretic peptide (NT-proBNP; HR: 1.001, 95\% CI 1.000-1.002, $\mathrm{p}=0.002$ ), and postoperative LVOT gradient (HR: $1.80,95 \%$ CI $1.08-3.02, \mathrm{p}=0.02$ ) were associated with cardiovascular death in this particular cohort. However, after adjustment for age, and sex, only NT-proBNP (HR: $1.002,95 \%$ CI $1.000-1.005, \mathrm{p}=0.02)$ and the glomerular filtration rate $\leq 80 \mathrm{ml} / \mathrm{min}$ (HR: $3.23,95 \%$ CI 1.34-7.24, $\mathrm{p}=0.047$ ) were independent risk factors for patients with T2DM (Table 5).

\section{Discussion}

Our study investigated the impact of T2DM on the midterm mortality of HOCM patients after septal myectomy. Several findings were included in the present study. First, HOCM patients with T2DM are more likely to develop pulmonary hypertension after surgery, and they have a higher incidence of NSVT even after septal myectomy. Second, HCM patients with and without T2DM have similar 5-year cardiovascular mortality after septal myectomy, but it is associated with higher SCD rate after surgery. Lastly, the baseline NT-proBNP and glomerular
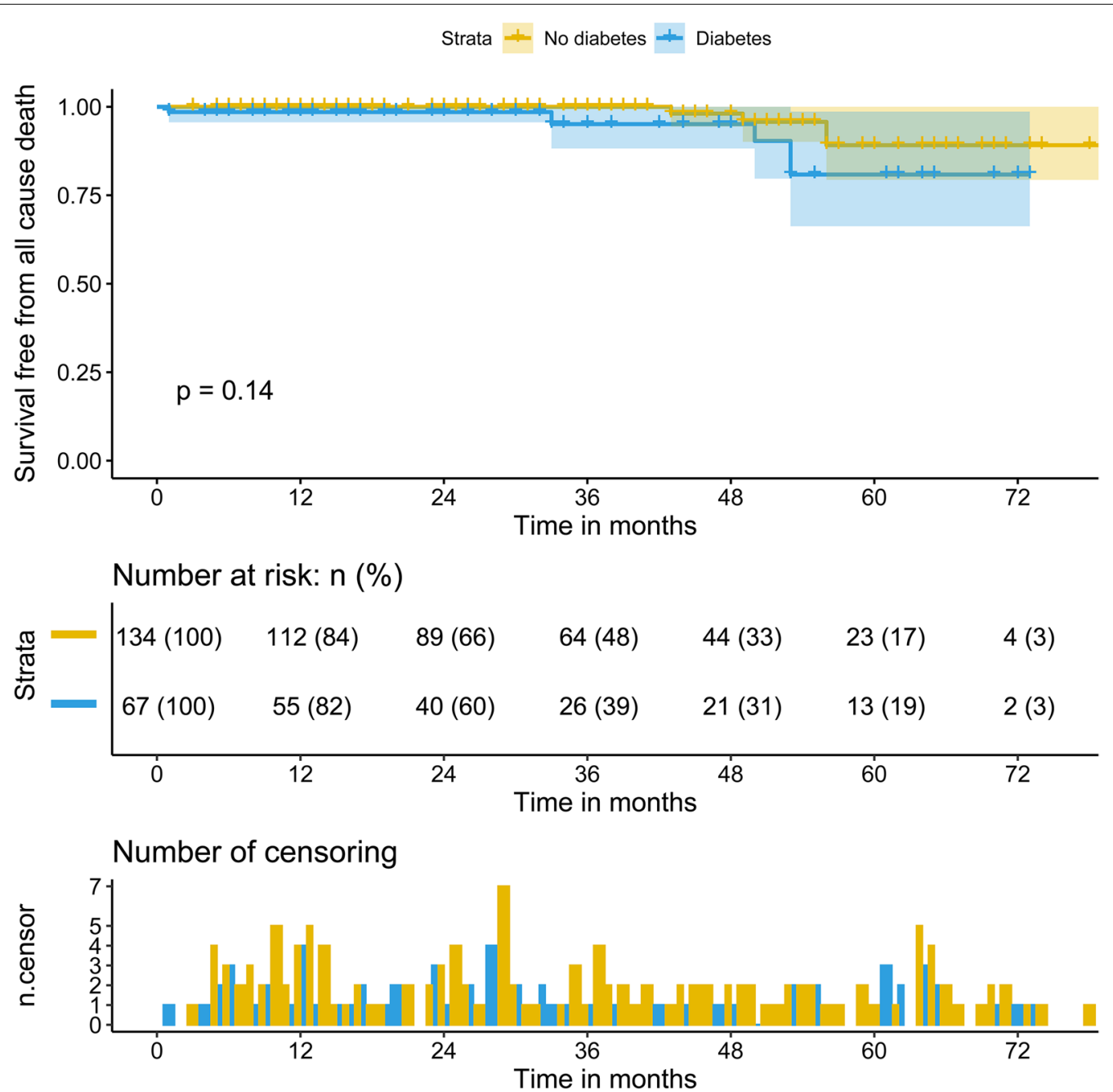

Fig. 1 Kaplan-Meier analysis of survival free from cardiovascular death between two groups 


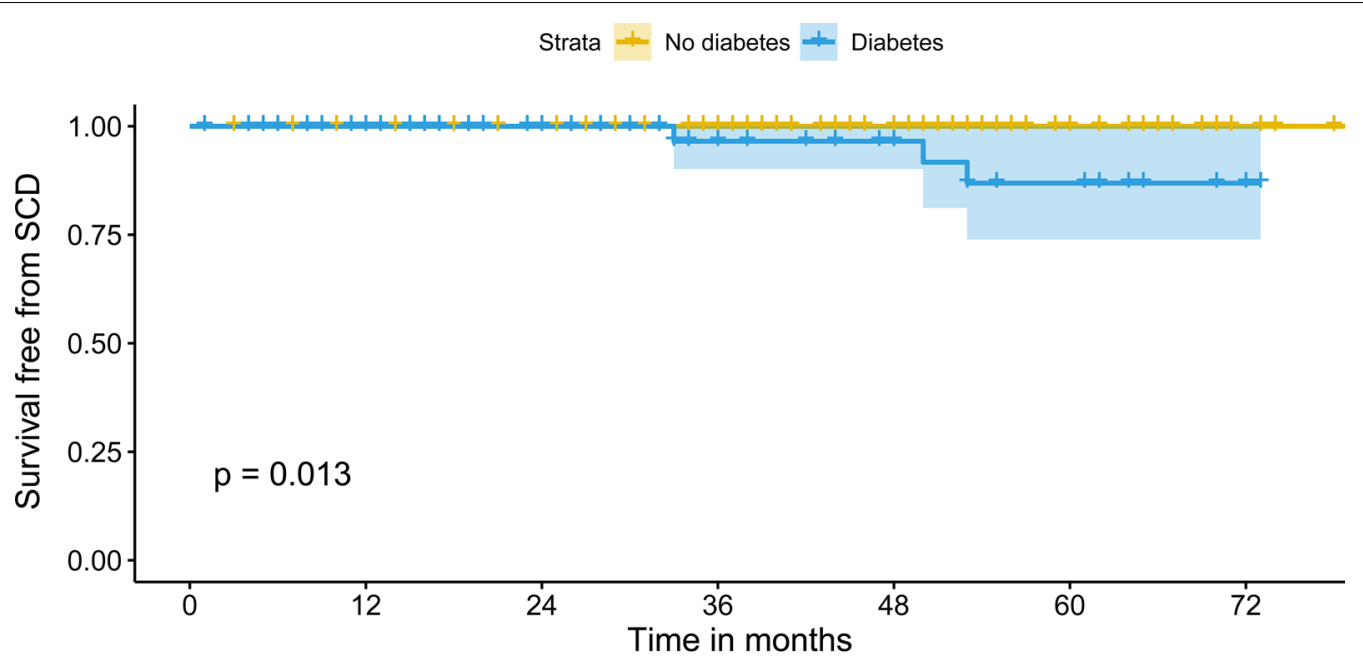

\begin{tabular}{|c|c|c|c|c|c|c|}
\hline \multicolumn{7}{|c|}{ Number at risk: $\mathrm{n}(\%)$} \\
\hline \begin{tabular}{l|l} 
(త) & $134(100)$
\end{tabular} & $112(84)$ & $89(66)$ & $64(48)$ & $44(33)$ & $23(17)$ & $4(3)$ \\
\hline$\ddot{\omega}=67(100)$ & $55(82)$ & $40(60)$ & $26(39)$ & $21(31)$ & $13(19)$ & $2(3)$ \\
\hline 0 & 12 & 24 & $\begin{array}{l}36 \\
36\end{array}$ & 48 & 60 & 72 \\
\hline
\end{tabular}

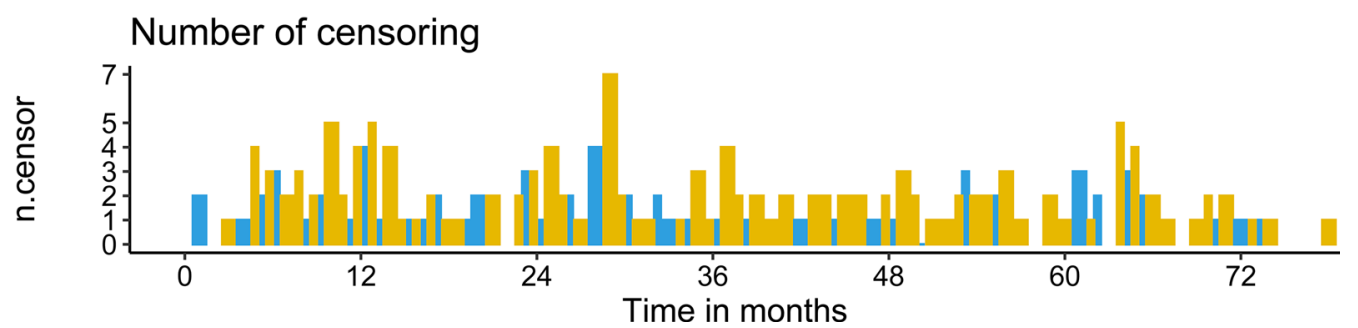

Fig. 2 Kaplan-Meier analysis of survival free from SCD between two groups. SCD sudden cardiac death

Table 5 Multivariate cox proportional Hazards Models for cardiovascular death in patients with T2DM

\begin{tabular}{|c|c|c|c|c|}
\hline \multirow[t]{2}{*}{ Variable } & \multicolumn{2}{|l|}{ Univariable } & \multicolumn{2}{|l|}{ Multivariate } \\
\hline & $\mathrm{HR}(95 \% \mathrm{Cl})$ & $\mathrm{p}$ & $\mathrm{HR}(95 \% \mathrm{CI})$ & $\mathrm{p}$ \\
\hline Age & $0.97(0.91-1.04)$ & 0.38 & & \\
\hline Male & $0.49(0.08-2.96)$ & 0.44 & & \\
\hline NT-Pro BNP & $1.001(1.000-1.002)$ & 0.002 & $1.002(1.000-1.005)$ & 0.02 \\
\hline $\mathrm{eGFR} \leq 80 \mathrm{ml} / \mathrm{min}$ & $4.83(1.42-19.36)$ & 0.02 & $3.23(1.34-7.24)$ & 0.04 \\
\hline NSVT & $1.51(1.31-1.73)$ & 0.03 & & \\
\hline Post-operative LVOT gradient & $1.80(1.08-3.02)$ & 0.02 & & \\
\hline
\end{tabular}

HR hazards ratio, eGFR estimated glomerular filtration rate, NSVT non-sustained ventricular tachycardia, LVOT left ventricular outflow tract gradient

filtration rate were independent risk factors among HCM patients with T2DM.

Only a few studies have been reported the impact of T2DM on the clinical outcomes of HCM patients.
Recently, one study reported the impact of DM on the clinical phenotype of HCM [3]. They showed that HCM patients with diabetes have a higher cardiovascular risk profile, a lower functional capacity, and more heart 
failure symptoms. In addition, they found that no difference in the rates of SCD in patients with or without DM. Actually, for patients who underwent septal myectomy have a lower mortality during perioperative period or a long-term result $[13,14]$. No study has reported on the influence of T2DM on HCM patients who underwent septal myectomy. However, the impact of DM on the clinical outcomes has been well studied in patients who underwent valve operations and coronary artery bypass. Many studies have reported that DM is associated with significantly worse outcomes after valve operations, and it is an independent predictor for long-term mortality after isolated aortic valve replacement $[5,7,15]$. In addition, previous studies have revealed that DM can increase the incidence of perioperative complications and heart failure and is an independent predictor of long-term mortality after coronary artery bypass $[6,16,17]$.

DM can affect the cardiovascular system of HCM patients through many aspects. First, chronic inflammation and microvascular changes within the kidney caused by DM can increase serum levels of inflammatory cytokines and impairment of renal function $[18,19]$. In our study, we found that the level of hs-CRP was high and the glomerular filtration rate was low in HCM patients with T2DM. Second, potential contributors of DM to the induction of cardiac arrhythmias, including hyperglycemia or glucose fluctuations and autonomic dysfunction, activate multiple mechanisms that contribute to the development of cardiac arrhythmias. In addition, structural remodeling, including changes in the electrical conduction of the heart, and fibrosis promote and potentiate the progression of arrhythmia [20]. The main finding of our study, i.e., the incidence rates of NSVT and AF were significantly higher in HOCM patients with T2DM than in those without T2DM, was consistent with those of previous studies. Both of these arrhythmias are associated with worse clinical outcomes for HOCM patients. Third, in our study, we found that the prevalence of pulmonary hypertension had no difference before operation, whereas the incidence of pulmonary hypertension after surgery increased significantly. Insulin resistance in DM patients may be a risk factor for pulmonary hypertension [21]. Moreover, in our study, we also found that RVEF was also high in HOCM patients with DM, which may reflect a decrease in right ventricular function. Lastly, the proportion of coronary artery bypass was high in HOCM patients DM. Chronic inflammation, insulin resistance, and dyslipidemia in DM can promote the development of coronary artery disease.

In our study, we found that the rates of predicted 3-year survival free from cardiovascular death are not different between HOCM patients with and without DM after septal myectomy, whereas the rate of predicted 3-year survival free from SCD was significantly lower in patients without DM than in those with DM. This is inconsistent with the previous study that HCM patients with diabetes have a higher risk of cardiovascular mortality and that there was no difference in SCD between patients with and without DM. The reason for this is that none of the patients underwent septal myectomy, and most HCM patients have no LVOT obstruction in that study. The incidence of NSVT was high in HOCM patients with DM even after surgery, which is a known risk factor for SCD $[22,23]$. In addition, we analyzed the variables associated with cardiovascular death in the subgroup of HOCM patients with DM. After adjustment for age, sex, and BMI, NT-proBNP and glomerular filtration rate were independent risk factors for cardiovascular death in this particular cohort. This is consistent with the previous studies that the NT-proBNP has been demonstrated as a novel marker for adverse clinical outcomes in HCM patients [24, 25]. Moreover, a previous study revealed that percutaneous transluminal septal myocardial ablation could improve the renal function of patients with $\mathrm{HCM}$, which suggests that these patients may have renal dysfunction [26]. In addition, DM can affect renal function through many ways [19].

DM is the main cause of heart failure, either secondary to cardiovascular disease or secondary to diabetic cardiomyopathy. HCM patients with DM have lower functional capacity and more heart failure symptoms. Therefore, in clinical practice, careful attention should be given for these particular patients who underwent septal myectomy, and they should be need to be followed up more closely, including monitoring of the effects of diabetes on other systems. In addition, because these patients have a relatively higher rate of SCD, we believe that ICD should be implanted more actively in patients with cardiac arrhythmia. By strengthening the management of these patients, we can reduce the complications and improve the prognosis of these patients.

\section{Limitations}

The present study has some limitations. First, this study is limited by its observational nature and the inherent limitations of a retrospective database study. Second, not all patients in our study underwent CMR, which limited our systematic analysis of myocardial fibrosis and right ventricular function in all patients. Third, although the patients in our study were from two medical centers, the number of HOCM patients with DM after septal myectomy is still small. Because of the small number of this particular cohort, we cannot analyze the difference in survival between DM patients who received medication and insulin. 


\section{Conclusions}

T2DM is associated with a higher SCD rate in a matched cohort with HOCM who underwent septal myectomy. However, it has no influence on the rate of cardiovascular death of these patients. In addition, the multivariable analysis revealed that the NT-proBNP and glomerular filtration rate were independent risk factors among HOCM patients with T2DM after surgery. The results of the present study suggest that HOCM patients with T2DM should be carefully monitored, especially its effects on renal function, after surgery.

\section{Supplementary information}

Supplementary information accompanies this paper at https://doi. org/10.1186/s12933-020-01036-1.

Additional file 1: Table S1. Relative multivariable imbalance $L 1$ and Summary of unbalanced covariates.

Additional file 2: Figure S1. Standardized difference before and after matching.

Additional file 3: Table S2. Baseline patient characters in unmatched cohort.

\section{Abbreviations}

BMI: Body mass index; Cl: Confidence interval; CMR: Cardiovascular magnetic resonance; CVD: Cardiovascular death; HCM: Hypertrophic cardiomyopathy; HOCM: Hypertrophic obstructive cardiomyopathy; HR: Hazards ratio; hs-CRP: High-sensitivity C-reactive protein; LGE: Late gadolinium enhancement; LV: Left ventricular; LVOT: Left ventricular outflow tract; NSVT: Non-sustained ventricular tachycardia; NT-proBNP: N-terminal pro-brain natriuretic peptide; SCD: Sudden cardiac death;T2DM: Type 2 diabetes mellitus.

\section{Acknowledgements}

Not applicable.

\section{Authors' contributions}

All authors were involved in the conception and design of the study and in the collection, analysis, and interpretation of the data. All authors reviewed the final manuscript. All authors read and approved the final manuscript.

\section{Funding}

This study was funded by National Natural Science Foundation of China (Grant No. 81570276) and National Natural Science Foundation of China (Grant No. 81770371).

\section{Availability of data and materials}

According to the Fuwai Hospital and Anzhen Hospital system, we are not allowed to share original study data publicly. Therefore, the datasets generated and/or analyzed during the current study are not publicly available.

\section{Ethics approval and consent to participate}

Approval of the Ethics Committee of Peking Union Medical College Affiliated Fuwai Hospital and Beijing Anzhen Hospital, Capital Medical University, was obtained before the start of the work.

\section{Consent for publication}

Not applicable.

\section{Competing interests}

The authors declare that they have no competing interests.

\section{Author details}

${ }^{1}$ Department of Cardiovascular Surgery Center, Beijing Anzhen Hospital, Capital Medical University, Beijing Institute of Heart, Lung and Blood Vascular
Diseases, No. 2, Anzhen Road, Chaoyang District, Beijing 100029, China. 2 Department of Cardiovascular Surgery, Mayo Clinic, Rochester, MN, USA. ${ }^{3}$ Department of Special Medical Treatment Center, State Key Laboratory of Cardiovascular Disease, Fuwai Hospital, National Center for Cardiovascular Diseases, Chinese Academy of Medical Sciences and Peking Union Medical College, Beijing, China. ${ }^{4}$ Department of Cardiovascular Surgery, State Key Laboratory of Cardiovascular Disease, Fuwai Hospital, National Center for Cardiovascular Diseases, Chinese Academy of Medical Sciences and Peking Union Medical College, No. 167, Beilishi Road, Xicheng District, Beijing 100037, China.

Received: 7 March 2020 Accepted: 7 May 2020

Published online: 13 May 2020

\section{References}

1. American College of Cardiology Foundation/American Heart Association Task Force on P, American Association for Thoracic S, American Society of E, American Society of Nuclear C, Heart Failure Society of A, Heart Rhythm S, Society for Cardiovascular A, Interventions, Society of Thoracic S, Gersh BJ, et al. 2011 ACCF/AHA guideline for the diagnosis and treatment of hypertrophic cardiomyopathy: a report of the American college of cardiology Foundation/American heart association task force on practice guidelines. J Thorac Cardiovasc Surg. 2011;142(6):e153-203.

2. Authors/Task Force m, Elliott PM, Anastasakis A, Borger MA, Borggrefe M, Cecchi F, Charron P, Hagege AA, Lafont A, Limongelli G, et al. 2014 ESC guidelines on diagnosis and management of hypertrophic cardiomyopathy: the task force for the diagnosis and management of hypertrophic cardiomyopathy of the European Society of Cardiology (ESC). Eur Heart J. 2014;35(39):2733-79.

3. Wasserstrum $Y$, Barriales-Villa R, Fernández-Fernández $X$, Adler Y, Lotan D, Peled Y, Klempfner R, Kuperstein R, Shlomo N, Sabbag A, et al. The impact of diabetes mellitus on the clinical phenotype of hypertrophic cardiomyopathy. Eur Heart J. 2018;40(21):1671-7.

4. Strain WD, Paldanius PM. Diabetes, cardiovascular disease and the microcirculation. Cardiovasc Diabetol. 2018;17(1):57.

5. Halkos ME, Kilgo P, Lattouf OM, Puskas JD, Cooper WA, Guyton RA, Thourani $\mathrm{VH}$. The effect of diabetes mellitus on in-hospital and long-term outcomes after heart valve operations. Ann Thorac Surg. 2010;90(1):124-30.

6. Kogan A, Ram E, Levin S, Fisman EZ, Tenenbaum A, Raanani E, Sternik L. Impact of type 2 diabetes mellitus on short- and long-term mortality after coronary artery bypass surgery. Cardiovasc Diabetol. 2018;17(1):151.

7. Ram E, Kogan A, Levin S, Fisman EZ, Tenenbaum A, Raanani E, Sternik L. Type 2 diabetes mellitus increases long-term mortality risk after isolated surgical aortic valve replacement. Cardiovasc Diabetol. 2019;18(1):31.

8. Wang S, Cui H, Yu Q, Chen H, Zhu C, Wang J, Xiao M, Zhang Y, Wu R, Hu S. Excision of anomalous muscle bundles as an important addition to extended septal myectomy for treatment of left ventricular outflow tract obstruction. J Thorac Cardiovasc Surg. 2016;152(2):461-8.

9. Guo HC, Wang Y, Dai J, Ren CW, Li JH, Lai YQ. Application of 3D printing in the surgical planning of hypertrophic obstructive cardiomyopathy and physician-patient communication: a preliminary study. J Thorac Dis. 2018;10(2):867-73.

10. Lang RM, Bierig M, Devereux RB, Flachskampf FA, Foster E, Pellikka PA, Picard MH, Roman MJ, Seward J, Shanewise JS, Solomon SD, Spencer KT, Sutton MS, Stewart WJ, et al. Recommendations for chamber quantification: a report from the American society of echocardiography's guidelines and standards committee and the chamber quantification writing group, developed in conjunction with the european association of echocardiography, a branch of the European Society of Cardiology. J Am Soc Echocardiogr. 2005;18(12):1440-63.

11. Green JJ, Berger JS, Kramer CM, Salerno M. Prognostic value of late gadolinium enhancement in clinical outcomes for hypertrophic cardiomyopathy. JACC Cardiovascular imaging. 2012;5(4):370-7.

12. Sabe MA, Sabe SA, Kusunose K, Flamm SD, Griffin BP, Kwon DH. Predictors and prognostic significance of right ventricular ejection fraction in patients with ischemic cardiomyopathy. Circulation. 2016;134(9):656-65.

13. Geske JB, Driver CN, Yogeswaran V, Ommen SR, Schaff HV. Comparison of expected and observed outcomes for septal myectomy in hypertrophic obstructive cardiomyopathy. Am Heart J. 2020;221:159-64. 
14. Desai MY, Bhonsale A, Smedira NG, Naji P, Thamilarasan M, Lytle BW, Lever HM. Predictors of long-term outcomes in symptomatic hypertrophic obstructive cardiomyopathy patients undergoing surgical relief of left ventricular outflow tract obstruction. Circulation. 2013;128(3):209-16.

15. López-de-Andrés A, de Miguel-Díez J, Muñoz-Rivas N, Hernández-Barrera V, Méndez-Bailón M, de Miguel-Yanes JM, Jiménez-García R. Impact of type 2 diabetes mellitus in the utilization and in-hospital outcomes of surgical mitral valve replacement in Spain (2001-2015). Cardiovasc Diabetol. 2019;18(1):135

16. Brush JE, Siraj ES, Kemp CD, Liverman DP, McMichael BY, Lamichhane R, Sheehan BE. Effect of diabetes mellitus on complication rates of coronary artery bypass grafting. Am J Cardiol. 2019;124(9):1389-96.

17. Takeji Y, Shiomi H, Morimoto T, Furukawa Y, Ehara N, Nakagawa Y, Kato T, Tazaki J, Kato ET, Yaku H, et al. Diabetes mellitus and long-term risk for heart failure after coronary revascularization. Circul J. 2020;84(3):471-8.

18. Liu C, Feng X, Li Q, Wang Y, Li Q, Hua M. Adiponectin, TNF-alpha and inflammatory cytokines and risk of type 2 diabetes: a systematic review and meta-analysis. Cytokine. 2016;86:100-9.

19. Anders HJ, Huber TB, Isermann B, Schiffer M. CKD in diabetes: diabetic kidney disease versus nondiabetic kidney disease. Nat Rev Nephrol. 2018;14(6):361-77.

20. Grisanti LA. Diabetes and arrhythmias: pathophysiology, mechanisms and therapeutic outcomes. Front Physiol. 2018;9:1669.

21. Fuso L, Pitocco D, Antonelli-Incalzi R. Diabetic lung, an underrated complication from restrictive functional pattern to pulmonary hypertension. Diabetes Metabol Res Rev. 2019;35(6):e3159.
22. Monserrat L, Elliott PM, Gimeno JR, Sharma S, Penas-Lado M, McKenna WJ. Non-sustained ventricular tachycardia in hypertrophic cardiomyopathy. J Am Coll Cardiol. 2003;42(5):873-9.

23. Di Salvo G, Pacileo G, Limongelli G, Baldini L, Rea A, Verrengia M, D'Andrea A, Russo MG, Calabro R. Non sustained ventricular tachycardia in hypertrophic cardiomyopathy and new ultrasonic derived parameters. J Am Soc Echocardiogr. 2010;23(6):581-90.

24. Coats CJ, Gallagher MJ, Foley M, O'Mahony C, Critoph C, Gimeno J, Dawnay A, McKenna WJ, Elliott PM. Relation between serum N-terminal pro-brain natriuretic peptide and prognosis in patients with hypertrophic cardiomyopathy. Eur Heart J. 2013;34(32):2529-37.

25. Song C, Wang S, Guo Y, Zheng X, Lu J, Fang X, Wang S, Huang X. Preoperative NT-proBNP predicts midterm outcome after septal myectomy. J Am Heart Assoc. 2019;8(4):e011075.

26. Maekawa Y, Jinzaki M, Tsuruta H, Akita K, Yamada Y, Kawakami T, Hayashida K, Yuasa S, Murata M, Fukuda K. Improved renal function in a patient with hypertrophic obstructive cardiomyopathy after multidetector computed tomography-guided percutaneous transluminal septal myocardial ablation. Int J Cardiol. 2015;181:349-50.

\section{Publisher's Note}

Springer Nature remains neutral with regard to jurisdictional claims in published maps and institutional affiliations.
Ready to submit your research? Choose BMC and benefit from:

- fast, convenient online submission

- thorough peer review by experienced researchers in your field

- rapid publication on acceptance

- support for research data, including large and complex data types

- gold Open Access which fosters wider collaboration and increased citations

- maximum visibility for your research: over 100M website views per year

At BMC, research is always in progress.

Learn more biomedcentral.com/submissions 